\title{
Optical test course teaching practice on WeChat public platform
}

\section{Yuegang Fu, Zhiying Liu}

Yuegang Fu, Zhiying Liu, "Optical test course teaching practice on WeChat public platform," Proc. SPIE 10452, 14th Conference on Education and Training in Optics and Photonics: ETOP 2017, 104521Y (16 August 2017); doi: $10.1117 / 12.2270968$

SDIE Event: 14th Conference on Education and Training in Optics and Photonics, ETOP 2017, 2017, Hangzhou, China 


\title{
Optical test course teaching practice on Wechat Public Platform
}

\author{
Fu Yuegang*a LiuZhiyinga \\ ${ }^{a}$ School of opto-electronic engineering, Changchun University of Science and Technology, No 7089 \\ Weixing Road,Changchun, Jilin, CHINA 130022
}

\begin{abstract}
With the development of information technological progress M-Learning and Micro-learning is becoming more and more popular among learners as a new micro-learning resources Micro-course is playing an more and more important role in daily learning. The students can create a new way of optical course learning through "wechat". Under the mutual interaction of two or more parties, the use of "wechat" can fully arouse the students' interest in learning, and make the subjective initiative of students. The ultimate goal of improving the level of students. In this paper, through the analysis of the current situation of undergraduate studentsusing the "WeChat", a new teaching model suitable for "optics" teaching is summarized, and the use of "WeChat" has been infiltrated into the teaching process, using science and technology to assist teaching. Students' interest in autonomous learning.
\end{abstract}

Key words: M-Learning,Micro-learning, wechat ,optical test courses, assist teaching

\section{INTRODUCTION}

With the continuous development of Internet technology and mobile communication technology, the new media with Internet and mobile Instant messaging software has had a great impact on all aspects of society, and it is changing people's lifestyles and habits.As of December 2016, the 39th "China Internet Development Statistics Report" released that Internet users number in China reached 731 million. There are 889 million active users using WeChat.The public platform account is more than 10 million, The number of third-party developers is 200,000. WeChat is a social media (instant messaging, commerce and payment services) application developed by Tencent. It was first released in 2011 and by 2016 it was one of the largest standalone messaging apps by monthly active users, However, as of 2017, WeChat has not been successful in penetrating international markets outside of China.

\section{The characteristics of WeChat suitable for aided teaching}

WeChat provides text messaging, hold-to-talk voice messaging, broadcast (one-to-many) messaging, video conferencing, video games, sharing of photographs and videos, and location sharing. It can exchange contacts with people nearby via Bluetooth, as well as providing various features for contacting people at random if desired (if people are open to it). It can also integrate with other social networking services such as those run by Facebook and Tencent QQ. Photographs may also be embellished with filters and captions, and a automatic translation service is available.

WeChat supports different ways of instant message, including text message, voice message, walkie talkie and stickers. Users can send previously saved or live pictures and videos, namecards of other users, coupons, lucky money packages, or current GPS location with friends either individually or in a group chat. WeChat's character stickers, such as Tuzki, resemble and compete with those of LINE, a Japanese messaging application.

WeChat as a new social media, to meet the living habits of undergraduate students, students have a strong appeal to the audience, and the platform can achieve one-to-many information dissemination, with a strong interactive and communication capabilities. According to statistics, about $90 \%$ of students have WeChat account, which for the use of

*Fuyg@cust.edu.cn; phone 86-0431-85582504; fax 86-0431-85582246; www.cust.edu.cn

14th Conference on Education and Training in Optics and Photonics: ETOP 2017, edited by Xu Liu,

Xi-Cheng Zhang, Proc. of SPIE Vol. 10452, 104521Y · (c) 2017 ICO, IEEE, OSA, SPIE

CCC code: $0277-786 \mathrm{X} / 17 / \$ 18 \cdot$ doi: $10.1117 / 12.2270968$

Proc. of SPIE Vol. $10452104521 \mathrm{Y}-1$ 
WeChat on the university course reform provides the basic conditions. The following characteristics of the WeChat make it more suitable for the teaching of undergraduate students.

\subsection{Wechat makes communication easier between teacher and student}

Traditional media only one-way output without two-way interaction. The Wechat open platform can use a variety of forms, the focus of real-time message push. In the teaching process, if the teacher uses the Wechat open platform to send messages to student, students can receive the message, with a strong synchronization. Students can view the message, you can reply to the message, the timely communication. Moreover, if you do not understand the problem needs to be discussed, the teacher can also create a group chat, participate in group chat learners can be discussed in time with other learners, communication, It can also be voice communication, like Face to face. If you meet the teacher or students are doing other work, you can also reply later.

\section{2 Wechat is suitable for the teaching of optical courses}

There are a wide variety of messages that can be sent on the public platform, which can be sent in text, picture, graphic, video, and voice. And QQ, micro-blogging, compared to everyone, WeChat more powerful. WeChat with a public platform, Moment, Games, Scan QR code, shake, Mesage in bottles, shopping and other nineteen specific functions, interactive forms of diversity so that Wechat make students become social darling, rich news content also allows students In the learning process to produce a more intense interest in learning. Such as the use of text and pictures can push the course content, can also be related to the course of teaching video or the need for intuitive content through the video to reflect.

\subsection{Wechat improved students' interest in learning}

WeChat as a personal instant communication tool, with distinctive personal characteristics. undergraduate students distinctive personality, keen to show themselves, through the release of friends circle status, their rich life "sun" out to meet the individual requirements of college students. For the Wechatopen platform, people only need to scan their interest in the WeChat public account of the two-dimensional code or search microblogging public account will be able to pay attention to the WeChat public account. Through the Wechatopen platform, you can publish background information related to the course, Technological frontier, Course related content, students can also get their own interested in reading content, news, activities and other content.

\subsection{WeChat allows students to use fragmented time.}

In the WeChat on the public platform, the size of the material resources are limited, for example: the text within 600 words, the picture does not exceed $2 \mathrm{M}$, the voice does not exceed $5 \mathrm{M}$, the video does not exceed $20 \mathrm{M}$, such a resource material miniaturization to a certain extent Enabling the audience to use the course resources on the platform for mobile learning. Very suitable for undergraduate students in the bus, subway and other short free time ,but also facilitate the digestion and absorption of content. So that students can use the fragmented time to learn the course, so that the effective complement of classroom teaching.

\subsection{WeChat is conducive to the realization of constructivist learning environment}

Constructivism learning theory holds that "context", "collaboration", "conversation" and "meaning construction" are the four attributes in the learning environment. Constructivism advocates learner-centered learning under the guidance of teachers. Not only emphasizes the learner's cognitive role, but also does not ignore the teacher's help and guidance. The WeChat through the Moment between the information session and exchange of interaction, for students to create such a learning situation, as an important way to build collaborative learning. WeChat can also organize problem-based learning, based on classroom discussion and completion of the study, to carry out cooperative learning and personalized learning, 
and ultimately through the meaning of construction, to achieve the improvement of professional standards.

\section{The use of WeChat teaching courses in optical test}

In the traditional professional teaching mode, in the limited class time, teachers instill a large number of teaching content, students are busy with other homework, teachers and students lack of discussion and communication between each other. In most cases students are passive. Students generally reflect that they rarely take the initiative to learn. The reasons are as follows,First, they do not know in addition to textbooks, where to obtain learning resources; Second, in addition to the examination, the knowledge I do not know how to use. The last is the process of learning problems can not be solved, So They gradually lost interest in study. We uses "WeChat" can help solve the above problems one by one. The specific approach is as follows,

\subsection{Develop the student's interest through the WeChat official account}

Through the establishment of WeChat public account, regularly push the course-related content, such as: PPT, video, science articles, students can choose their favorite learning resources. Through the promotion of relevant books and open class website so that students can access the learning resources, but also sent technological frontier, so that students can understand the development of science and technology in this field, to stimulate students interest to learning. So that Students take the initiative to learn, and the teacher becomes the provider of information.

\subsection{Increased communication and collaboration}

Groupchat of Wechat can be through the following three forms. Teachers can establishment of groupchat of Wechats in one class. The teacher organizes the discussion of the topic in the group, or answers a question. In the course of the discussion, students can at any time put forward their own views, efforts to use knowledge to explain the point of view. The second is for teachers arranged group operations, such as group speech, students can be established within the group to discuss and study. After the establishment of groupchat of Wechat, you can use WeChat to discuss the main content, and then meet again to integrate. Third, students can freely develop a learning group in the field of personal interest, and through the group of Groupchat to discuss and exchange. In the group of students can monitor each other, encourage each other to jointly solve the difficulties and problems of learning and common progress.

\section{3 through the private letter to solve student problems}

The application of WeChat for students in the learning process to produce problems that provide an effective and timely solution. Students can be in the classroom teaching, online learning and discussion of the problems arising from many problems, through the intercom function in the form of private letters to ask the teacher. This will not only solve the students' questions, but also to protect the privacy of students. Teachers and students between the deep communication, which can effectively compensate for the current lack of interactive teaching in classroom , to stimulate students' interest in learning and improve learning enthusiasm. This way of learning exchange, not only for students to solve the problem in time to learn, but also to extend the classroom beyond the classroom space. Teachers can communicate through the private letter between teachers and students, the students found in the study of the problems encountered, to find out the common problems in teaching, and targeted to adjust the teaching plan, so targeted, improve classroom teaching results. In addition, teachers and students through micro-communication and communication, and further enhance mutual understanding and trust between teachers and students is bound to promote the improvement of teaching quality.

\subsection{Use the groupchat to learn independently}

students can be published in the WeChat Moment and learning related to the log. The log can be reproduced or created, the content form can choose an optical test program, the measurement principle, the measuring instrument can even be a 
simple concept. There are a lot of information in the network to provide students with a wealth of reading materials, teachers can also course-related video, PPT, lesson plans uploaded to the network for students . In order to avoid duplication, students need to read the published content before the release of information, to a certain extent, to ensure that the amount of reading and log publishing significance. In the process of reprint and reply, students need to sum up the knowledge in the log, the use of Chinese or English writing skills have also been trained to effectively achieve the purpose of learning.

\section{Method and suggestion}

When students lack the subjective initiative of learning, teachers in the initial use of WeChat-assisted teaching students need to be mandatory. Until the students develop good habits, gradually by the mandatory request to encourage. Teachers can also use the Wechat or WeChat official account to the students to arrange learning tasks, to encourage students in the corresponding interface and the appropriate time to respond accordingly, urging students to study the problem under the class. Such as: can be cited 2016 Problems for the 29th IYPT 2016 Title 15. The problem is that Contactless Calliper----Invent and construct an optical device that uses a laser pointer .Students discuss the evaluation of the parameters of the test options and error analysis. This will not only exercise the ability of students to solve the problem autonomously, but also save the classroom time

\section{CONCLUSIONS}

In summary, through the WeChat to create a learning environment, students and students can be enhanced, students and teachers to communicate with each other and counseling,Share the learning experience and learning content, effectively improve and consolidate the classroom teaching effect, improve the subjective learning of students Initiative and ability to solve problems. At the same time, WeChat also provides a wealth of learning resources to make up for optical test courses .The traditional teaching mode of the short board, can improve the quality of optical test teaching.

\section{REFERENCES}

[1]Based on the analysis of the impact of micro channel on the interaction, Journal of Higher Education,2015,vol(19)

[2]https://en.wikipedia.org/wiki/WeChat

[3] 'The39 ${ }^{\text {th }}$ China Internet Development Statistics Report' http://www.cnnic.net.cn/hlwfzyj/ 